\title{
Postmarathon paradox: insulin resistance in the face of glycogen depletion
}

\author{
JUHA A. TUOMINEN, PERTTI EBELING, RAYMOND BOUREY, \\ LASZLO KORANYI, ANTTI LAMMINEN, JUHANI RAPOLA, TIMO SANE, \\ HELENA VUORINEN-MARKKOLA, AND VEIKKO A. KOIVISTO \\ Departments of Medicine, Radiology, and Pediatrics, Helsinki University Central Hospital, \\ FIN-00290 Helsinki, Finland; Washington University School of Medicine, \\ St. Louis, Missouri 63110; and Department of Metabolism, Hungarian Heart Center, \\ H-8231 Balatonfüred, Hungary
}

\begin{abstract}
Tuominen, Juha A., Pertti Ebeling, Raymond Bourey, Laszlo Koranyi, Antti Lamminen, Juhani Rapola, Timo Sane, Helena Vuorinen-Markkola, and Veikko A. Koivisto. Postmarathon paradox: insulin resistance in the face of glycogen depletion. Am. .J. Physiol. 270 (Endocrinol. Melab. 33): E336-E343, 1996.-Acute physical exercise enhances insulin sensitivity in healthy subjects. We examined the effect of a $42-\mathrm{km}$ marathon run on insulin sensitivity and lipid oxidation in 19 male runners. In the morning after the marathon run, basal serum free fatty acid concentration was 2.2 -fold higher, muscle glycogen content $37 \%$ lower $(P<0.01)$, glycogen synthase fractional activity $56 \%$ greater $(P<0.01)$, and glucose oxidation reduced by $43 \%(P<0.01)$, whereas lipid oxidation was increased by $55 \%(P<0.02)$ compared with the control study. During euglycemic-hyperinsulinemic clamp, whole body glucose disposal was decreased by $12 \%$ $(P<0.01)$ because of a $36 \%$ lower glucose oxidation rate $(P<$ $0.05)$, whereas the rate of lipid oxidation was 10 -fold greater $(P<0.02)$ than in the control study. After the marathon, muscle glycogen content correlated positively with lipid oxidation $(r=0.60, P<0.05)$ and maximal aerobic power $\left(\dot{\mathrm{V}}_{2 \text { peak }}\right.$; $r=0.61, P<0.05)$. $\dot{\mathrm{V}}_{2 \text { peak }}$ correlated positively with basal lipid oxidation $(r-0.57, P<0.05)$. In conclusion, 1$)$ after the marathon run, probably because of increased lipid oxidation, the insulin-stimulated glucose disposal is decreased despite muscle glycogen depletion and the activation of glycogen synthase; 2) the contribution of lipid oxidation in energy expenditure is increased in proportion to physical fitness; 3 ) these adaptations of fuel homeostasis may contribute to the maintenance of physical performance after prolonged exercise.
\end{abstract}

exercise; glucose uptake; insulin sensitivity; lipid metabolism; glycogen; glycogen synthase

A MARATHON RUN is one of the most extreme conditions for humans to stress physiological homeostasis. In particular, there are great demands for the adaptation of fuel homeostasis. If a marathon run is performed at an intensity close to $65 \%$ of maximal aerobic power $\left(\dot{\mathrm{V}}_{\mathrm{O}_{2 \text { peak }}}\right)$, the total energy consumption is in the range of 2,400-2,800 kcal $(10,000-12,000 \mathrm{~kJ})$, which is equal to or more than the energy consumption during the whole day in most people (28). A number of studies have addressed how the body will adjust to this stress during exercise $(1,3,13,28)$. When exercise is performed after an overnight fast, muscle glycogen and blood-borne glucose are the major sources of fuel during the $1 \mathrm{st} \mathrm{h}$ (1). After that, there is a shift to greater fat utilization, and the contribution of free fatty acids (FFA) increases progressively when the exercise is prolonged (1). However, if carbohydrate is given during exercise, the respiratory quotient remains above 0.90 , indicating a high continuous use of carbohydrate as a fuel (26).

The recovery of fuel homeostasis after a marathon run is less well known. If exercise is performed in the fasting state, the enhanced fat oxidation is still going on after exercise, leading to a decrease in glucose utilization (20). The duration of increased fat oxidation is not known. Neither is it known whether enhanced fat utilization occurs if carbohydrate is ingested during exercise as is done during the marathon run. Because a fast repletion of muscle glycogen stores is crucial for the recovery of performance, it is important to know the duration of enhanced postexercise fat utilization and its effect on the repletion of glycogen stores. In untrained individuals, glucose disposal was decreased 48 $\mathrm{h}$ after they had performed eccentric exercise (downhill running), whereas no effect on glucose uptake was secn after concentric exercise (18). Because eccentric exercise causes muscle soreness and high elevations in serum creatine kinase concentrations, a decrease in glucose uptake after eccentric exercise was considered to be a consequence of muscle damage rather than a metabolic adaptation $(18,22)$.

Long-term exercise leads to glycogen depletion, which is an important stimulator of glycogen synthesis regardless of ambient insulin concentrations $(8,13)$. On the other hand, we have recently demonstrated an inverse relationship between serum FFA concentration and muscle glycogen content as determined by the euglycemic insulin clamp (9). These data suggest that after the marathon run there are two factors with partly opposing effects on glycogen synthesis: low glycogen content stimulates the glycogen synthase activity, whereas high FFA levels seem to regulate the amount of glycogen in muscle when the glycogen stores are filling. The net outcome of these opposite effects is not known. Consequently, the present study was planned to examine, in healthy humans, the rates of glucose and fat utilization, muscle glycogen synthesis, and their interrelationships the day after a competitive marathon run.

\section{METHODS}

\section{Subjects}

Nineteen male runners with the mean age of $39 \pm 2 \mathrm{yr}$, body mass index (BMI) of $22.8+0.3 \mathrm{~kg} / \mathrm{m}^{2}$, and maximal 
aerobic power $\left(\dot{\mathrm{V}}_{2 \text { peak }}\right)$ of $47 \pm 2 \mathrm{ml} \cdot \mathrm{kg}^{-1} \cdot \mathrm{min}^{-1}$ (range $37.4-55.9 \mathrm{ml} \cdot \mathrm{kg}^{-1} \cdot \mathrm{min}^{-1}$ ) participated in the study. All subjects were healthy, and none of them was using any medication. The subjects had been training for the marathon by running $40-60 \mathrm{~km} / \mathrm{wk}$ for $\geq 4 \mathrm{mo}$. For 2 days before the control study, the subjects did not participate in any training and had a diet containing 250-300 g carbohydrate per day. The purpose, nature, and possible risks of the study were explained to all subjects before informed consent was obtained. The study protocol was approved by the Ethical Committee of the Helsinki University Hospital.

\section{Design}

The study consisted of three parts. First, blood samples were taken before, during, and after the $42-\mathrm{km}$ marathon run. Second, euglycemic insulin clamp with muscle biopsies and indirect calorimetry was done on the day after the marathon run. Third, a control insulin clamp study was performed after a resting day $2-3 \mathrm{wk}$ after the marathon run. In addition, $\dot{\mathrm{V}}_{2 \text { peak }}$ was determined in each subject to characterize physical fitness and, in a part of the group, muscle histological examination and magnetic resonance imaging (MRI) from thighs were performed to reveal any muscle damage.

\section{Maralhon Sludy}

Each subject ran a competitive $42-\mathrm{km}$ marathon race starting at 3:30 P.M. One hour before, in the middle of the race $(20 \mathrm{~km})$, and immediately after the race, a blood sample (45-ml each) was taken from the antecubital vein. The mean duration of the race was $3 \mathrm{~h}$ and $34 \mathrm{~min}$ (range from $2 \mathrm{~h}$ and $40 \mathrm{~min}$ to $4 \mathrm{~h}$ and $45 \mathrm{~min}$ ). The food intake before, during, and after the race was according to individual habits, without any influence by the investigators. On the basis of the interview, mean carbohydrate intake in the preceding day was $510 \pm$ $70 \mathrm{~g}$, and during the marathon day it was $237+68 \mathrm{~g}$, from which $48 \%$ was ingested before, $10 \%$ during, and $42 \%$ after the race. The estimated energy intake during the marathon day was $3,230 \pm 230 \mathrm{kcal}$.

\section{Insulin Clamp}

After an overnight 10- to 12-h fast, both after the day of marathon run and after a resting control day, we performed a 240-min euglycemic insulin clamp study in 14 subjects, as previously described $(6,8)$. One catheter was inserted into an antecubital vein for the infusion of insulin and glucose, and another was inserted into a heated hand vein (kept in a box at $60^{\circ} \mathrm{C}$ ) for the sampling of arterialized blood and other specimens. Insulin (Actrapid Human, Novo Nordisk, Copenhagen, Denmark) was infused in a primed-continuous rate $[9 \mathrm{nmol}$ (1.5 $\mathrm{mU}) \cdot \mathrm{kg}^{-1} \cdot \mathrm{min}^{-1}$ for $240 \mathrm{~min}$. Plasma glucose was maintained at the fasting level, with $20 \%$ glucose infused at a variable rate based on plasma glucose determinations from the arterialized blood measured at 5- to 10-min intervals. Because hepatic glucose production is totally suppressed with even lower insulin infusion rates than those employed here, the glucose infusion rate corrected for changes in plasma glucose concentration equals the rate of glucose disposal. In the subjects not participating in the clamp studies $(n=5)$, only fasting blood samples were taken.

\section{Oxidation and Energy Expenditure Measures}

Glucose, lipid, and protein oxidation and energy expenditure were determined in 12 subjects with indirect calorimetry (Deltatrac Metabolic Monitor, Datex, Helsinki, Finland) be- fore and during the last $40 \mathrm{~min}$ of insulin infusion, as previously described from our laboratory (8). The constants to calculate glucose and lipid oxidation from respiratory exchange data have been given previously (11). The protein oxidation rate during the study was estimated from the urinary urea nitrogen excretion $(1 \mathrm{~g}$ nitrogen $=6.25 \mathrm{~g}$ protein). Energy expenditure was calculated from the sum of substrate oxidation rates multiplied by their respective caloric equivalents (11). Nonoxidative glucose disposal is defined as the difference between total and oxidative glucose disposal.

\section{Muscle Biopsies}

A percutaneous biopsy was performed in all 19 subjects on the morning after the marathon run and after a resting control day. In the subjects participating in the clamp study $(n=14)$, the biopsy was performed in the opposite legs before and at the end of the insulin clamp study, similarly in both studies. In the subjects not participating in the clamp studies $(n=5)$, only one biopsy was performed after an overnight fast in the morning after the marathon run and after the resting control day. The specimen (100-150 mg) was taken from $\mathrm{m}$. vastus lateralis with a Bergström needle under local anesthesia (1\% lidocaine). The samples were removed from muscle with suction by a syringe attached to the needle. For biochemical studics, a sample was immediately placed in liquid $\mathrm{N}_{2}$, where it was stored until analyzed. For histological studies, a sample was immediately placed into $2.5 \%$ phosphate-buffered glutaraldehyde solution ( $\mathrm{pH} 7.2$ ) for several hours, changed to $0.05 \mathrm{M}$ phosphate buffer, and stored at $4^{\circ} \mathrm{C}$ until further processed.

\section{Muscle Assays}

Muscle glycogen and glycogen synthase assays were done as previously described (8). The muscle samples were freezedried and dissected free from blood and connective tissue. Approximately $10 \mathrm{mg}$ of muscle were powdered, weighed, and used for glycogen determination. Muscle powder was extracted with $\mathrm{KOH}$ and neutralized, glycogen was hydrolyzed with amyloglycosidase, and the liberated glucose was analyzed with the glucose oxidase method. Glycogen concentration is expressed as millimoles per kilogram of dry muscle. Glycogen synthase activity was measured by a fluorometric method, as described previously (8). This method determines the production of uridine diphosphate (UDP) from the incorporation of UDP-glucose in glycogen. Samples and blanks were incubated for $15 \mathrm{~min}$ at $37^{\circ} \mathrm{C}$ with 0.1 and $10 \mathrm{mmol} / /$ glucose 6-phosphate (G-6-P). The enzyme activity determined at 0.1 $\mathrm{mmol} / \mathrm{l} \mathrm{G}-6-P$ is called glycogen synthase activity, and the ratio of the activities at 0.1 and $10 \mathrm{mmol} / / \mathrm{G}-6-P$ is called glycogen synthase fractional activity. The assay was linear for protein concentration in the homogenate. Protein concentration was determined according to Lowry et al. (23). After the marathon run, both glycogen and glycogen synthase activity were determined in 16 subjects in the basal state and in 12 subjects after the insulin clamp. In the control study the number of basal and postclamp determinations was 15 and 11 , respectively.

\section{Preparation of Tissue RNA and Quantitation of Muscle DNA, GLUT-4, and Glycogen Synthase mRNA and GLUT-4 Protein Levels}

Measurements were done as previously described (8). Briefly, total tissue RNA was extracted with a guanidine thiocyanate water-saturated phenol extraction method. After the determination of absorbance at 260 and $280 \mathrm{~nm}$, an 
aliquot of RNA was run on minigel to verify the integrity of RNA preparations. Aliquots of total RNA (5.0 and $10.0 \mu \mathrm{g})$ were dissolved in $5.6 \%$ formaldehyde, $10 \times \mathrm{SSC}(1.5 \mathrm{~mol} / \mathrm{l}$ $\mathrm{NaCl}, 0.015 \mathrm{~mol} / \mathrm{h}$ sodium citrate, $\mathrm{pH} 7.0$ ) and blotted onto Hybond-N membranes (Amersham International). Membranes were hybridized with the appropriate probes $(\sim 5 \times$ $10^{6} \mathrm{cpm} / \mathrm{ml}$ ) for $18 \mathrm{~h}$ at $60^{\circ} \mathrm{C}$ in $50 \%$ formamide, $5 \times \mathrm{SSPE}$ (0.75 mol// NaCl, $\left.50 \mathrm{mmol} / / \mathrm{NaH}_{2} \mathrm{PO}_{4}, 5 \mathrm{mmol} / \mathrm{l} \mathrm{EDTA}\right)$, and $3 \times$ Denhardt's $0.1 \%$ sodium dodecyl sulfate (SDS) and then washed in $0.1 \times \mathrm{SSC}, 0.1 \% \mathrm{SDS}$ at $65^{\circ} \mathrm{C}$. The blots were exposed to Fuji RX film (Fuji Photo Film, Tokyo, Japan) at $-70^{\circ} \mathrm{C}$ with use of intensifying screens (Cronex Lightening Plus, Du Pont, Wilmington, DE) for various periods of time. The amount of GLUT-4 and glycogen synthase mRNA present in each sample was measured by densitometric analysis, by comparing the intensity of sample dots with dilutions of appropriate cDNA standard dots as described (8). The template for glycogen synthase cRNA probe was a Hind III linearized Bluescript SK+ plasmid containing human glycogen synthase cDNA, and the cDNA insert was used as standard. DNA concentrations of tissue homogenate were measured with a DNA fluorometer (model TKO 100, Hoefer Scientific, San Francisco, CA) with Hoechst 33258 dye (Poly-

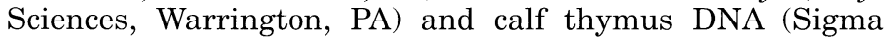
Chemical) as standard. After both the marathon and the control days, GLUT-4 protein was determined from 17 subjects in the basal state and from 12 subjects (11 at control study) after the insulin clamp. Because of the small sample size, muscle glycogen synthase mRNA was quantified after the marathon day in 8 subjects ( 6 studied with the clamp) and after the control day in 7 subjects ( 5 with the clamp).

\section{Immunoblotting}

Muscle was homogenized (Polytron, Brinkman, Westbury, $\mathrm{NY})$ on ice at high speed for $45 \mathrm{~s}$ in HES buffer $(20 \mathrm{mM}$ $N$-2-hydroxyethylpiperazine- $N^{\prime}$-2-ethanesulfonic acid, $1 \mathrm{mM}$ EDTA, $250 \mathrm{mM}$ sucrose, $\mathrm{pH} 7.4 ; 1: 40$, wt/vol). The protein concentration was determined by a method based on the reaction with bicinchoninic acid (Pierce Europe), and 50- $\mathrm{gg}$ samples were subjected to SDS-polyacrylamide gel electrophoresis. Protein was electrophoretically transferred to nitrocellulose paper (MilliBlot-SDE System, Millipore, American Bionctics). Nitroccllulose shects were incubated with phosphate-buffered saline ( $\mathrm{pH} 7.4$ ) containing $50 \mathrm{mg} / \mathrm{ml}$ of powdered milk (Valio, Helsinki, Finland) for $60 \mathrm{~min}$ at $22^{\circ} \mathrm{C}$ and thereafter with a polyclonal antibody specific for the GLU'I-4 carboxy-terminal (F349) after washing with ${ }^{125}$ I-labeled donkey anti-rabbit immunoglobulin G antibody (Amersham, Arlington Heights, IL). Quantitation was performed by generation of autoradiographs and densitometry against a gray scale standard with use of standard software (Image 1.32f, National Technical Information Service, Springfield, VA).

\section{Muscle Histology}

The muscle pieces $\left(\sim 1 \mathrm{~mm}^{3}\right)$ stored in phosphate buffer were postfixed in $\mathrm{OsO}_{4}$, dehydrated in graded ethanols, and embedded in epoxy resin with conventional techniques of preparing tissue for light microscopy. Several plastic sections, $1 \mu \mathrm{m}$ in thickness, were cut of each sample with glass knives, stained with toluidine blue, and studied under a light microscope.

$\dot{\mathrm{V}} \mathrm{O}_{2 \text { peak }}$

$\dot{V} \mathrm{O}_{2 \text { peak }}$ was determined using a work-conducted upright exercise test with an electrically braked cycle ergometer (Bosch ERG 220, Robert Bosch, Berlin, Germany) combined with continuous analysis of expiratory gases and minute ventilation (EOS-Sprint, Erich Jaeger, Würtzburg, Germany). The mixed expiratory gas was sampled for analysis, and $\mathrm{O}_{2}$ and other gas exchange parameters $\left(\mathrm{CO}_{2}\right.$ and respiratory quotient) were automatically calculated and printed out at 30 -s intervals. $\dot{\mathrm{V}} \mathrm{O}_{2 \text { peak }}$ was defined as the $\dot{\mathrm{V}}_{2}$ of the highest $30 \mathrm{~s}$ of the exercise. Maximal exercise levels obtained exceeded the anaerobic threshold as indicated by the respiratory gas exchange ratio over 1.10 at the end of exercise in all subjects.

\section{$M R I$}

MRI was performed with a $1.0-\mathrm{T}$ superconductive imager (Magneton SP42, Siemens, Erlangen, Germany). $\mathrm{T}_{1^{-}}$and $\mathrm{T}_{2}$-weighted spin echo images were obtained in the axial plane. MRI was done in four subjects immediately after the marathon and repeated the next morning, 10-12 h later. Control MRI was done in the same subjects 2 wk later.

\section{Other Determinations}

Glucose in the plasma and glycogen assays was determined with a glucose oxidase method by use of a Beckman glucose analyzer (Beckman Instruments, Fullerton, CA). The determinations of FFA concentrations in plasma were done by the fluorometric method (25). Serum insulin, growth hormone, cortisol, and glucagon were all determined with radioimmunoassays as indicated in our previous studies (8). Blood hemoglobin, serum creatine, aspartate aminotransferase (AST), and creatine kinase (CK) were measured using the standard methods in our laboratory.

\section{Statistical Methods}

Comparison between the groups was made with MannWhitney's two-sample rank-sum test. Wilcoxon's test was used in the calculations between paired items. The correlation analysis was performed with Spearman's test. A multiple regression analysis was used for revealing interrclationships between multiple variables. $P$ values $<0.05$ were considered significant. Results are given as means $\pm \mathrm{SE}$.

\section{RESULTS}

\section{Blood Determinations During and After the Marathon}

Plasma glucose concentration remained unchanged, whereas serum insulin concentration decreased and the counterregulatory hormones (cortisol, glucagon, growth hormone) all increased significantly (Table 1). In addition, there was a 7.3-fold elevation in serum FFA concentration. In the morning after the marathon run, serum FFA concentration was still 2.2-fold higher than on the control morning. During the insulin infusion studies, serum FFA levels decreased similarly in both studies $(P<0.001)$ but were still higher at the postexercise study (the average between 30 and $240 \mathrm{~min}, 122 \pm$ 6 vs. $108 \pm 6 \mu \mathrm{mol} / \mathrm{l}, P<0.01$, respectively). Serum CK concentration rose 3 -fold during the race, and the increase continued, leading to a 13 -fold elevation the next morning compared with the prerace concentration. A similar pattern was seen in the rise of serum AST concentration, with a 2.5-fold elevation in the morning after the marathon run (Table 1). The changes of CK and AST during the run correlated also with $\dot{\mathrm{V}}_{\mathrm{O}_{\text {peak }}}(r=0.51, P<0.05$ and $r=0.70, P<0.001$, 
Table 1. Changes in blood substrate and hormone and enzyme concentrations during the marathon run, after the marathon, and after a resting day

\begin{tabular}{|c|c|c|c|c|c|}
\hline & \multicolumn{3}{|c|}{ During Marathon } & \multirow[b]{2}{*}{ Next Morning } & \multirow{2}{*}{$\begin{array}{c}\text { Control } \\
(2 \text { wk later })\end{array}$} \\
\hline & $0 \mathrm{~km}$ & $20 \mathrm{~km}$ & $42 \mathrm{~km}$ & & \\
\hline Glucose, $\mathrm{mmol} / \mathrm{l}$ & $6.0 \pm 0.3$ & $5.7 \pm 0.3$ & $6.3 \pm 0.3$ & $5.1 \pm 0.1$ & $5.3 \pm 0.1$ \\
\hline Free fatty acids, $\mu \mathrm{mol} / /$ & $311+43$ & $1400+114^{*}$ & $2278+185^{*}$ & $1082+86^{*} \ddagger$ & $484+52^{*}$ \\
\hline Insulin, $\mathrm{pmol} / /$ & $68 \pm 12$ & $32 \pm 7 \dagger$ & $46 \pm 11 \dagger$ & $25 \pm 3 \dagger$ & $28 \pm 4^{*}$ \\
\hline Cortisol, $\mathrm{nmol} / \mathrm{l}$ & $534 \pm 39$ & $489 \pm 63$ & $1116 \pm 61^{*}$ & $374 \pm 26^{*}$ & $435 \pm 38$ \\
\hline Glucagon, $\mathrm{ng} / \mathrm{l}$ & $86 \pm 5$ & $104 \pm 10 \dagger$ & $149 \pm 8^{*}$ & $86 \pm 6$ & $76 \pm 6 \dagger$ \\
\hline Growth hormone, $\mu \mathrm{g} / \mathrm{l}$ & $3.6 \pm 1.4$ & $9.6 \pm 4.1 \dagger$ & $7.5 \pm 1.0$ & $2.2 \pm 1.3^{*}$ & $4.4 \pm 1.5$ \\
\hline Aspartate aminotransferase, U/ & $43 \pm 3$ & $43 \pm 3 \dagger$ & $54 \pm 4^{*}$ & $104 \pm 23 \dagger$ & $40 \pm 40$ \\
\hline Creatine kinase, $\mathrm{U} / \mathrm{l}$ & $163 \pm 19$ & $233 \pm 47 *$ & $494 \pm 122^{*}$ & $2184 \pm 755^{* \ddagger}$ & $176 \pm 21$ \\
\hline Creatinine, $\mu \mathrm{mol} / \mathrm{l}$ & $97 \pm 3$ & & $129 \pm 5^{\dagger}$ & & \\
\hline Hemoglobin, $g / l$ & $148 \pm 2$ & & $151 \pm 2 \dagger$ & & \\
\hline
\end{tabular}

Values are means $\pm \mathrm{SE}$. Significantly different from basal $(0 \mathrm{~km})$ value $(* P<0.01 ; \dagger P<0.05)$ or from control day value $(\dagger P<0.01)$.

respectively). There was a small but significant increase in blood hemoglobin and serum creatine concentrations, thus reflecting a slight dehydration during the run (Table 1).

\section{Glucose Disposal}

Fasting plasma glucose and serum insulin concentrations were similar in the morning after the marathon run and on the control day (Table 1). During hyperinsulinemia (30-240 min of insulin infusion), steady-state plasma glucose $(5.2 \pm 0.1$ vs. $5.1 \pm 0.1 \mathrm{mmol} / \mathrm{l})$ and insulin concentrations $(670 \pm 19$ vs. $682 \pm 29 \mathrm{pmol} / \mathrm{l})$ were similar during the postmarathon and the control clamp studies, respectively. In the basal state, the rate of glucose oxidation was $43 \%$ lower after the marathon than on the control day $(4.8 \pm 1.1$ vs. $8.3 \pm 1.1$ $\mu \mathrm{mol} \cdot \mathrm{kg}^{-1} \cdot \min ^{-1}, P<0.05$, respectively). During insulin infusion (30-240 min), the whole body glucose disposal was $12 \%$ lower after the marathon than on the control day $\left(57.7 \pm 2.1 \mathrm{vs} .65 .4 \pm 2.6 \mu \mathrm{mol} \cdot \mathrm{kg}^{-1} \cdot \mathrm{min}^{-1}\right.$, $P<0.01$, Fig. 1). This difference is accounted for by the $36 \%$ lower glucose oxidation rate $(17.2 \pm 1.3$ vs. $23.3 \pm$ $1.1 \mu \mathrm{mol} \cdot \mathrm{kg}^{-1} \cdot \mathrm{min}^{-1}, P<0.02$ ), because nonoxidative glucose disposal rates were similar in both studies $\left(40.5 \pm 2.4\right.$ vs. $42.2 \pm 2.9 \mathrm{\mu mol} \cdot \mathrm{kg}^{-1} \cdot \mathrm{min}^{-1}$, Fig. 1$)$. When the two studies were combined, the basal serum FFA levels correlated inversely with the whole body glucose disposal rate $(r=-0.40, P<0.05)$. On the

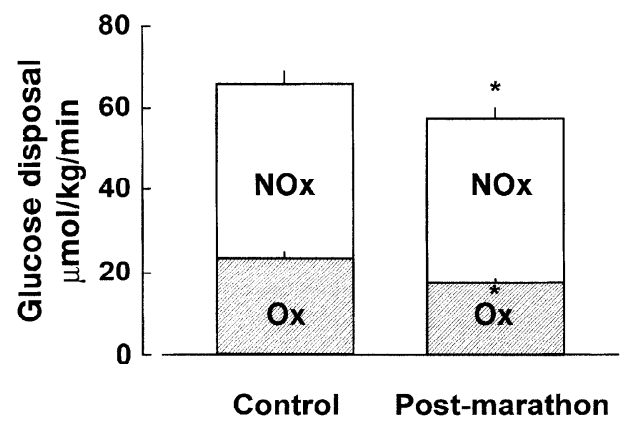

Fig. 1. Total (whole bar), oxidative (Ox, shaded area), and nonoxidative (NOx, open area) glucose disposal rate as determined with an euglycemic insulin clamp and indirect calorimetry the day after a competitive marathon run and after a resting control day. $* P<0.05$ vs. respective value on control day. control day, basal oxidative glucose disposal correlated inversely with serum FFA concentration (Fig. 2), and when the two studies were combined $(r=-0.61, P<$ $0.01)$, but not on the day after the marathon $(r=0.02$, not significant).

\section{Lipid Oxidation}

After the marathon, lipid oxidation was $55 \%$ higher in the basal state and 10-fold higher during the last 30 min of insulin infusion compared with the control day (Fig. 3). There was a close inverse relationship between lipid and glucose oxidation both in the basal state $(r=$ $-0.90, P<0.001)$ and during insulin infusion $(r=$ -0.97, $P<0.001$ ) after the marathon and on the control day $(r=-0.67$ and $-0.70, P<0.05$, in both, respectively). In the control study, basal FFA levels correlated positively with basal lipid oxidation $(r=$ $0.52, P<0.05$ ). After the marathon, basal lipid oxidation correlated inversely with total glucose disposal $(r=-0.58, P<0.05)$, and $\dot{\mathrm{V}}_{2 \text { peak }}$ correlated positively with lipid oxidation both in the basal state and during hyperinsulinemia $(r=0.57$ and $0.55, P<0.05$ in both, respectively). Of enhanced lipid oxidation after the marathon, $44 \%$ was explained by $\dot{\mathrm{V}}_{\mathrm{O}_{2 \text { peak }}}$ and duration of the race together $(P<0.05)$, whereas $23 \%$ was explained by $\dot{\mathrm{VO}}_{2 \text { peak }}$ alone $(P<0.05)$ in a multipleregression analysis.

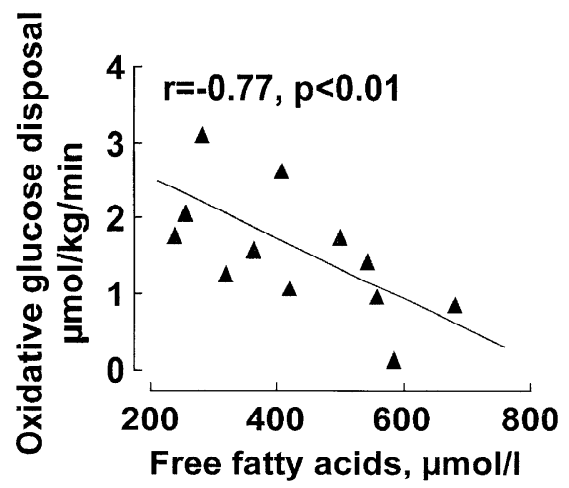

Fig. 2. Correlation between fasting serum free fatty acid concentration and basal glucose oxidation rate as determined after the resting control day. 


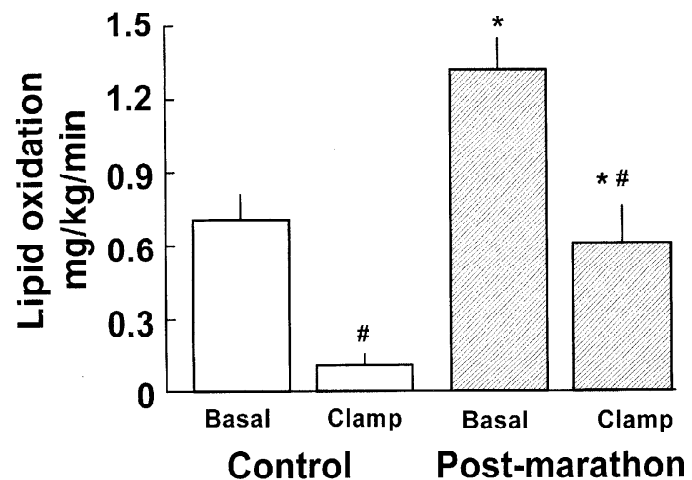

Fig. 3. Rate of lipid oxidation determined with indirect calorimetry after an overnight fast in the morning after the marathon and after a resting control day. Studies were done in basal state and during the last $30 \mathrm{~min}(210-240 \mathrm{~min})$ of insulin clamp study. ${ }^{*} P<0.01$ vs. respective value on control day; $\# P<0.02$ vs. value in basal state.

\section{Energy Expenditure}

On the morning after the marathon, basal energy expenditure was $6 \%$ higher than on the control morning $(5.5 \pm 0.1$ vs. $5.2 \pm 0.1 \mathrm{~kJ} / \mathrm{min}$, respectively, $P<$ 0.002 , Fig. 4). The increase was entirely due to a higher lipid oxidation after the marathon, whereas protein oxidation was equal in both studies. During insulin infusion, energy expenditure increased similarly after the marathon (to $6.1 \pm 0.1 \mathrm{~kJ} / \mathrm{min}, P<0.001$ ) and on the control day (to $5.9+0.1 \mathrm{~kJ} / \mathrm{min}, P<0.001$ ). $\dot{\mathrm{V}} \mathrm{O}_{2 \text { peak }}$ and energy expenditure during hyperinsulinemia were positively related after the marathon $(r=0.52, P<$ 0.05). Energy expenditure during hyperinsulinemia was not related to simultaneous serum FFA concentration.

\section{Muscle Determinations}

Glycogen. On the morning after the marathon, basal muscle glycogen content was $37 \%$ lower than on the control day (Fig. 5). Muscle glycogen during the clamp studies increased significantly by $20 \%(P=0.02)$ when the two studies were pooled together, but the changes were not significant when analyzed separately. The postclamp muscle glycogen content was $32 \%$ lower after the marathon than after the respective concentration on the control day $(P<0.01)$. On the postmarathon

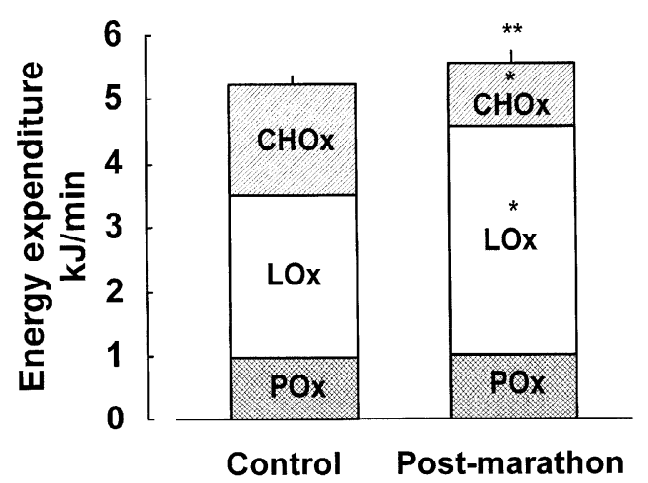

Fig. 4. Basal energy expenditure on control and postmarathon days. POx, protein oxidation; LOx, lipid oxidation; ChOx, glucose oxidation. $* P<0.05$ and $* * P<0.002$ vs. control day.

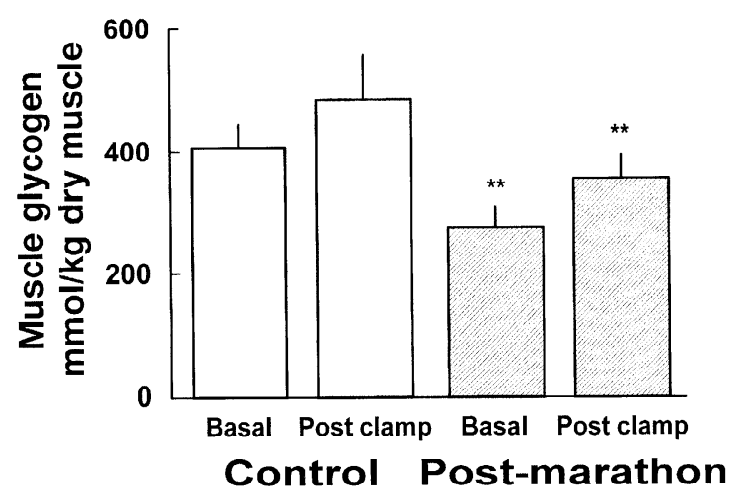

Fig. 5. Muscle glycogen content in basal state and after insulin clamp on day after marathon race and after the resting control day. $* * P<0.01$ vs. respective value on control day.

and control days, the basal muscle glycogen content correlated inversely with respective fasting serum FFA $(r=-0.68, P<0.01$ and $r=-0.64, P<0.05)$. The basal muscle glycogen content after the marathon correlated inversely with serum insulin $(r=-0.60, P<$ 0.05 ) concentrations and positively with basal lipid oxidation $(r=0.60, P<0.05)$, whereas the rise in muscle glycogen content after the marathon correlated positively with total glucose disposal rate $(r=0.74, P<$ 0.01 ) and inversely with the basal rate of lipid oxidation $(r=0.62, P<0.05) . \dot{\mathrm{V}} \mathrm{O}_{2 \text { peak }}$ correlated on the morning after the marathon with the basal glycogen content $(r=$ $0.61, P<0.05)$.

Glycogen synthase. The day after the marathon, basal muscle glycogen synthase activity was $73 \%$ higher $(P<0.05)$ and the fractional activity was $56 \%$ higher $(P<0.01)$ than on the control day (Table 2). During insulin infusion, glycogen synthase fractional activity increased in both studies, whereas the synthase activity rose only after the marathon day. However, the fractional activity after insulin infusion was still higher after the marathon than on the control day (Table 2). After the marathon, basal muscle glycogen synthase fractional activity correlated positively with total glucose disposal $(r=0.63, P<0.05)$ and the rise in muscle glycogen content $(r=0.62, P<0.05)$ but inversely with basal glycogen content $(r=-0.59, P<0.05)$, basal lipid oxidation rate $(r=-0.72, P<0.01)$, and $\mathrm{V}_{O_{2 \text { peak }}}(r=$ $-0.87, P<0.01)$. After the marathon there was a negative correlation between muscle glycogen synthase fractional activity and energy expenditure both in the basal state $(r=-0.76, P<0.01)$ and at the end of the $\operatorname{clamp}(r=-0.65, P<0.05)$.

Glycogen synthase mRNA. After the marathon, the basal muscle glycogen synthase mRNA content was $30 \%$ lower than the control value, as expressed per total RNA (Table 2). During insulin infusion, glycogen synthase mRN $\Lambda$ increased after the marathon, when $\mathrm{cx}$ pressed either per total RNA (increase $82 \%$ ) or per total DNA (130\%), whereas no change occurred in the control study (Table 2 ).

Glucose transport protein (GLUT-4) and its mRNA. Basal muscle glucose transport protein concentration was virtually indistinguishable after the marathon and in the control study $(675 \pm 53$ vs. $678 \pm 74$ densitomet- 
Table 2. Glycogen synthase activity and mRNA determined in m. quadriceps femoris on control day and the day after marathon

\begin{tabular}{|c|c|c|c|c|}
\hline & \multicolumn{2}{|c|}{ Control } & \multicolumn{2}{|c|}{ Postmarathon } \\
\hline & Basal & Hyperinsulinemia & Basal & Hyperinsulinemia \\
\hline $\begin{array}{l}\text { Glycogen synthase activity } \\
\text { G-6- } P, \mathrm{mmol} / 1\end{array}$ & $(n=15)$ & $(n=11)$ & $(n=16)$ & $(n=12)$ \\
\hline 0.1 & $16.5 \pm 2.6$ & $31.6 \pm 3.8$ & $31.2 \pm 2.4^{*}$ & $35.0 \pm 2.4 \dagger$ \\
\hline 10.0 & $30.3 \pm 3.7$ & $43.6 \pm 4.2$ & $40.0 \pm 2.0$ & $40.9 \pm 3.0$ \\
\hline Fractional activity $0.1 / 10$ & $0.48 \pm 0.07$ & $0.72 \pm 0.05 \dagger$ & $0.78 \pm 0.04 *$ & $0.87 \pm 0.04^{*} *$ \\
\hline Glycogen synthase mRNA & $(n=7)$ & $(n=5)$ & $(n=8)$ & $(n=6)$ \\
\hline $\mathrm{OD} / \mu \mathrm{g}$ RNA & $31.8 \pm 5.2$ & $23.6 \pm 3.4$ & $22.1 \pm 2.8^{*}$ & $40.2 \pm 4.6^{* \dagger}$ \\
\hline $\mathrm{OD} / \mu \mathrm{g}$ DNA & $207 \pm 64$ & $183 \pm 56$ & $107 \pm 19$ & $245 \pm 59 \dagger$ \\
\hline
\end{tabular}

Values are means $\pm \mathrm{SE}$; units for glycogen synthase activity are $\mathrm{nmol} \cdot \mathrm{min}^{-1} \cdot \mathrm{mg}$ protein ${ }^{-1}$, and those for $\mathrm{mRNA}$ are optical density $(\mathrm{OD}) / \mu \mathrm{g}$ RNA or DNA; $n$, no. of samples. G-6-P, glucose 6-phosphate. Significant differences from respective sample on control day: $* P<0.05$; from basal sample on same day: $\dagger P<0.05 ; \ddagger P<0.01$.

ric U/mg protein, respectively). In both studies, the values remained unchanged after insulin infusion $(699 \pm 58$ vs. $625 \pm 57$ densitometric U/mg protein, respectively). GLUT-4 mRNA content, regardless of whether it was expressed per total RNA or total DNA, was similar in the morning after the marathon and after the resting day (data not shown) and remained unchanged during insulin clamp studies on both days.

MRI and muscle histology. No abnormal signal changes indicating muscle damage were detected in the postmarathon $\mathrm{T}_{2}$-weighted images, and there was no difference between the postmarathon and control day MRIs. There were no indications of muscle damage in the histological structure of the muscle samples studied.

\section{DISCUSSION}

A number of studies have demonstrated that major regulators of muscle glycogen synthesis in healthy humans are ambient glycogen concentration and glycogen synthase activity $(5,8,9,13,14)$. These studies, however, have been performed in subjects not exposed to exercise, or the exercise has been of short duration (14). In the current study after the marathon run, muscle glycogen content was decreased and the synthase activity increased. In addition, basal muscle glycogen synthase fractional activity correlated inversely with basal glycogen content and positively with the rise in glycogen, and the rise in glycogen was also related to total glucose disposal rate. During hyperinsulinemia, glycogen synthase activity, enzyme fractional activity, and mRNA content all increased significantly. However, these changes or the associations with glucose metabolism did not lead to a significantly greater rise in muscle glycogen content or the whole body glucose disposal after the marathon compared with the control study. Neither did we see any changes in muscle GLUT-4 protein content, although its mRNA level increased significantly by hyperinsulinemia after the marathon. These data suggest that, after the marathon, other mechanisms overcame the regulatory role of low muscle glycogen content and increased glycogen synthase activity to stimulate oxidative glucose dis- posal and glucose storage as glycogen beyond a level seen in the control study.

During the marathon, there was a significant rise in serum glucagon, cortisol, and growth hormone concentrations. However, none of these hormones was elevated on the morning after the race. Thus, provided there is any long-term effect, counterregulatory hormones probably had no major contribution to the decrease in insulin-mediated glucose disposal observed the day after the marathon run.

The range of individual duration of the race varied greatly. Because of the competitive status of the race, the relative intensity can be considered about the same in each individual. Thus the differences in relative exercise intensity probably do not contribute to the results of this study.

Regarding muscle damage, the race was run on streets with a hard surface, and the runners had elevated levels of CK and AST. These elevations were

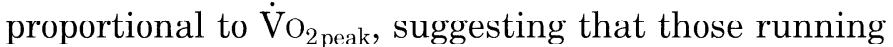
with the highest intensity also had the greatest muscle damage. In previous studies, it has been suggested that muscle damage can contribute to decreased insulinmediated glucose disposal immediately after exercise $(18,22)$. However, we were unable to detect any muscle damage in the histological or MRI examination of the muscle. Because these methods are sensitive in revealing muscle damage (21), we can exclude alterations in muscle structure as a major contributing factor to reduced muscle glucose uptake the day after the marathon.

The diet before, during, and after exercise was based on individual habits of the runners. The total carbohydrate uptake on the marathon day did not differ from a normal day, probably leading to a negative energy balance on the day of exercise. After the race, the subjects ingested $\sim 40 \%$ of the carbohydrates of that day with the last intake at 10 P.M., so the fasting period before the insulin clamp study did not differ from the control situation. The total energy intake during the marathon day was slightly more than the energy spent during the race (28). Thus, although the energy balance for the whole day may have been slightly negative, the 
difference was probably small. If so, the differences in the energy balance between marathon and control days had no major influence on the increased lipid oxidation the day after the marathon (12).

It is well established that during a long-term exercise and a few hours after the end of running, the major source of fuel is FFA $(1,4,7,19,20,29,30)$. In the current study, lipid oxidation rate the day after the marathon was still nearly 2 -fold elevated in the basal state and 10-fold greater during hyperinsulinemia compared with the control day. These data thus indicate that FFA are still the major alternative fuel on the day after long-term exercise. High FFA concentrations were observed despite the carbohydrate meal the subjects had ingested after the race. However, serum FFA levels during hyperinsulinemia were only $13 \%$ higher after the marathon, and the correlations between serum FFA and lipid oxidation were weak. It is thus possible that the 10-fold-greater FFA utilization rate after the race is not all blood borne but that FFA can be derived also from intramuscular triglycerides (24). A correlation between $\dot{\mathrm{V}}_{2 \text { peak }}$ and lipid oxidation also suggests that those with the best fitness maintain a greater fat utilization after exercise.

After the marathon, the rate of basal lipid oxidation was inversely associated with total glucose disposal. In addition, basal muscle glycogen synthase fractional activity and the rate of lipid oxidation were inversely related. Although the correlations do not prove causal relationship, the data suggest that after long-term exercise there is an ongoing high fat oxidation that can reduce glucose oxidation, nonoxidative glucose metabolism, and glycogen synthase activity. Thus the glucosefatty acid or Randle cycle (27) still operates actively the day after the marathon, and the use of FFA as a fuel may be one of the main reasons for decreased glucose utilization after the marathon. Regarding the cellular mechanisms of the interaction, a number of factors can be involved. First, the long-chain fatty acyl-CoA inhibits pyruvate dehydrogenase complex, decreasing glucose oxidation $(10,15)$. Second, exercise decreases malonyl-CoA concentration (31), which may facilitate fatty acid oxidation during and after exercise by removing the inhibition on carnitine palmitoyltransferase I. Third, exercise increases both acutely (17) and by training effect (16) the activity of muscle lipoprotein lipase, leading to enhanced FFA availability. The activity of muscle lipoprotein lipase is considered one indicator of muscle insulin sensitivity (17) that is related with $\dot{V}_{\mathrm{O}_{2 \text { peak }}}(8)$. Thus, in subjects with high $\dot{\mathrm{V}}_{\mathrm{O}_{2 \text { peak }}}$, enhanced lipoprotein lipase activity provides FFA as a fuel that will be utilized rather than glucose because of intracellular changes described earlier. In the present study, $\dot{\mathrm{V}} \mathrm{O}_{2 \text { peak }}$, basal lipid oxidation, and muscle glycogen content were positively related after the marathon. These associations suggest that individuals with good physical performance have a high lipid oxidation rate and greater capacity for sparing circulating glucose and muscle glycogen.

Energy expenditure, or the thermogenesis caused by metabolic processes, was elevated after the marathon run both in the basal state and during hyperinsulinemia. High energy expenditure could be explained by the excess postexercise $\mathrm{O}_{2}$ consumption caused by the high intensity of the marathon run (2). The correlations between high energy expenditure, high muscle glycogen content, and low synthase activity were probably not directly causal ones but mediated by a third factor, high lipid oxidation rate.

Regarding the physiological importance of our observations, increased fat utilization as a fuel in the muscle the day after prolonged exercise can be considered as a means to spare both circulating glucose for brain and muscle glycogen stores for acute bouts of exercise. Under ancient conditions, in which a man had to exercise and fight for food, these mechanisms may have been critical for survival. This hypothesis is supported by the observation of this study that the better the physical fitness, the greater was the lipid oxidation rate on the day after the marathon.

The authors acknowledge the skillful technical assistance of Elisa Kostamo and Riitta Kärkkäinen, the help of Dr. Monica Löfman in the insulin clamp studies and of Dr. Anssi Sovijärvi in $\dot{V}_{O_{2 p e a k}}$ determinations, and the use of facilities in Helsinki City Marathon's medical unit provided by Dr. Antti Cederberg.

The study was supported by the Finnish Ministry of Education; the Sigfrid Juselius, Novo Nordisk, Paulo, Yrjö Jahnsson, and Maud Kuistila Foundations; the Orion Corporations Scientific Foundation; and the Research Institute of Helsinki University Hospital.

Address for reprint requests: J. A. Tuominen, Helsinki Univ. Central Hospital, Dept. of Medicine, os 112, FIN-00290 Helsinki, Finland.

Received 19 June 1995; accepted in final form 18 September 1995.

\section{REFERENCES}

1. Ahlborg, G., P. Felig, L. Hagenfeldt, R. Hendler, and J. Wahren. Substrate turnover during prolonged exercise in man: splanchnic and leg metabolism of glucose, free fatty acids and amino acids. J. Clin. Invest. 53: 1080-1090, 1974.

2. Bahr, R., and O. M. Sejersted. Effect of intensity of exercise on excess postexercise $\mathrm{O}_{2}$ consumption. Metab. Clin. Exp. 40: 836$841,1991$.

3. Bergstrom, J., and E. Hultman. A study of the glycogen metabolism during exercise in man. Scand. J. Clin. Lab. Invest. 19: 218-228, 1967.

4. Coggan, A. R., W. M. Kohrt, R. J. Spina, D. M. Bier, and J. O. Holloszy. Endurance training decreases plasma glucose turnover and oxidation during moderate-intensity exercise in men. $J$. Appl. Physiol. 68: 990-996, 1990.

5. Danforth, W. H. Glycogen synthase activity in skeletal muscle: interconversion of two forms and control of glycogen synthesis. $J$. Biol. Chem. 240: 588-593, 1965.

6. DeFronzo, R. A., J. D. Tobin, and R. Andres. Glucose clamp technique: a method for quantifying insulin secretion and resistance. Am. J. Physiol. 237 (Endocrinol. Metab. Gastrointest. Physiol. 6): E214-E223, 1979.

7. Devlin, J. T., and E. S. Horton. Metabolic fuel utilization during postexercise recovery. Am. J. Clin. Nutr. 49, Suppl. 5: 944-948, 1989.

8. Ebeling, P., R. Bourey, L. Koranyi, J. A. Tuominen, L. C. Groop, J. Henriksson, M. Mueckler, A. Sovijarvi, and V. A. Koivisto. Mechanism of enhanced insulin sensitivity in athletes. Increased blood flow, muscle glucose transport protein (GLUT-4) concentration, and glycogen synthase activity. J. Clin. Invesl. 92: 1623-1631, 1993.

9. Ebeling, P., and V. A. Koivisto. Non-esterified fatty acids regulate lipid and glucose oxidation and glycogen synthesis in healthy man. Diabetologia 37: 202-209, 1994.

10. Erfle, J. D., and F. Sauer. The inhibitory effects of acylcoenzyme A esters on the pyruvate and alpha-oxoglutarate 
dehydrogenase complexes. Biochim. Biophys. Acta 178: 441-452, 1969.

11. Ferrannini, E. The theoretical bases of indirect calorimetry: a review. Metab. Clin. Exp. 37: 287-301, 1988.

12. Flatt, J.-P. Use and storage of carbohydrate and fat. Am. J. Clin. Nutr. 61, Suppl. 1: 952S-959S, 1995.

13. Ivy, J. L. Muscle glycogen synthesis before and after exercise. Sports Med. 11: 6-19, 1991.

14. Ivy, J. L., B. A. Frishberg, S. W. Farrell, W. J. Miller, and W. M. Sherman. Effects of elevated and exercise-reduced muscle glycogen levels on insulin sensitivity. J. Appl. Physiol. 59: $154-159,1985$

15. Kiechle, F. L., T. Malinski, and K. H. Moore. Insulin action: implications for the clinical laboratory. Lab. Med. 21: 565-573, 1990.

16. Kiens, B., and H. Lithell. Lipoprotein metabolism influenced by training-induced changes in human skeletal muscle. J. Clin. Invest. 83: 558-564, 1989.

17. Kiens, B., H. Lithell, K. J. Mikines, and E. A. Richter. Effects of insulin and exercise on muscle lipoprotein lipase activity in man and its relation to insulin action. J. Clin. Invest. 84: 1124-1129, 1989.

18. Kirwan, J. P., R. C. Hickner, K. E. Yarasheski, W. M. Kohrt, B. V. Wiethop, and J. O. Holloszy. Eccentric exercise induces transient insulin resistance in healthy individuals. J. Appl. Physiol. 72: 2197-2202, 1992.

19. Koivisto, V. A. The physiology of marathon running. Sci. Prog. 70: 109-127, 1986.

20. Krzentowski, G., F. Pirnay, A. S. Luyckx, N. Pallikarakis, M. Lacroix, F. Mosora, and P. J. Lefebvre. Metabolic adaptations in post-exercise recovery. Clin. Physiol. 2: 277-288, 1982.

21. Lamminen, A. E., P. E. Hekali, E. Tiula, I. Suramo, and O.A. Korhola. Acute rhabdomyolysis: evaluation with magnetic resonance imaging compared with computed tomography and ultrasonography. Br. J. Radiol. 62: 326-330, 1989.
22. Lash, J., M. Sherman, and S. Bloomfield. Muscle soreness: glucose and insulin response. Med. Sci. Sports Exercise Suppl. 19: $575,1987$.

23. Lowry, O. H., N. J. Rosebrough, A. L. Farr, and R. J. Randall. Protein measurement with the Folin phenol reagent. $J$. Biol. Chem. 193: 265-275, 1951.

24. Maggs, D. G., R. Jacob, F. Rife, R. Lange, P. Leone, M. J. During, W. V. Tamborlane, and R. J. Sherwin. Interstitial fluid concentrations of glycerol, glucose, and amino acids in human quadriceps muscle and adipose tissue. J. Clin. Invest. 96: 370-377, 1995.

25. Miles, J., R. Glasscock, .J. Aikens, J. Gerich, and M. Haymond. A microfluorometric method for the determination of free fatty acids in plasma. J. Lipid Res. 24: 96-99, 1983.

26. O'Brien, M. J., C. A. Viguie, R. S. Mazzeo, and G. A. Brooks. Carbohydrate dependence during marathon running. Med. Sci. Sports Exercise 25: 1009-1017, 1993.

27. Randle, P. J., P. B. Garland, C. N. Hales, and E. A. Newsholme. The glucose fatty acid cycle: its role in insulin sensitivity and the metabolic disturbances of diabetes mellitus. Lancet 1 : 785-789, 1963 .

28. Sherman, W. M., D. L. Costill, W. J. Fink, F. C. Hagerman, L. E. Armstrong, and T. F. Murray. Effect of a 12.2-km footrace and subsequent rest or exercise on muscle glycogen and enzymes. .J. Appl. Physiol. 55: 1219-1224, 1983.

29. Stein, T. P., R. W. Hoyt, M. O. Toole, M. J. Leskiw, M. D. Schluter, R. R. Wolfe, and W. D. Hiller. Protein and energy metabolism during prolonged exercise in trained athletes. Int. $J$. Sports. Med. 10: 311-316, 1989.

30. Walker, M., B. G. Cooper, C. Elliott, J. W. Reed, H. Orskov, and K. G. Alberti. Role of plasma non-esterified fatty acids during and after exercise. Clin. Sci. Lond. 81: 319-325, 1991.

31. Winder, W. W., J. Arogyasami, R. J. Barton, I. M. Elayan, and $\mathbf{P .}$ R. Vehrs. Muscle malonyl-CoA decreases during exercise. J. Appl. Physiol. 67: 2230-2233, 1989. 